\title{
Beyond crisis talk: Interrogating migration and crises in Europe
}

\section{Nick Dines}

European University Institute, Italy

\author{
Nicola Montagna \\ Middlesex University, UK
}

\section{Elena Vacchelli}

University of Greenwich, UK

\begin{abstract}
Commencing with some recent examples drawn from Anglophone media, this introductory article reflects on the multiple ways in which crisis and migration have been interconnected over the last decade in public discourse, political debates and academic research. It underlines how crisis has not simply become a key descriptor of specific events, but continues to operate as a powerful narrative device that structures knowledge of migration and shapes policy decisions and governance structures. It explains the rationale for choosing Europe as a multidimensional setting for investigating the diverse links between migration and crisis. It ends with a summary of the contributions that are divided into four thematic strands: relationships between the economic crisis and migrant workers and their families; the Mediterranean in crisis; political and public discourses about the post-2015 'migration crisis'; and ethnographies of everyday experiences of the 'refugee crisis' on the part of migrants, activists and local people.
\end{abstract}

\section{Key words}

Crisis; migration; Europe; economic crisis; refugee crisis; crisis talk.

On 18 December 2017 the US weekly magazine Time published an article in its 'Ideas' section by the new Federal Chancellor of Austria, Sebastian Kurz. In this article, the rising star of Europe's Centre Right reiterated the tough stance on migration that he had already taken as foreign minister in the previous SPÖ-ÖVP coalition government. According to Kurz, although progress had been made in closing the 'Western Balkans route' and introducing a code of conduct for NGO search-and-rescue missions in the southern central Mediterranean, 
'a robust control of the European Union's external borders remains a prerequisite [...] Stopping and returning illegal migrants to their countries of origin must become standard procedure' (Kurz 2017). In order to outline his diagnosis, Kurz resorted ten times to the word 'crisis'. He repeatedly conjured up associated motifs such as 'loss of control', 'overwhelmed by developments', 'this time was different', 'a huge challenge for our country', 'regain control' and 'find solutions', alongside the classic Western view of Africa as a continent in perennial crisis (with a 'population [...] expected to double in the next 30 years reaching 2 billion people') and hence the ultimate source of Europe's continuing predicament. For Kurz, the 'migration and refugee crisis' was not just an objective state of affairs: it was also a political tactic to present himself to a global Anglophone readership as a firm but measured state leader.

In late 2017, 'migration' and 'crisis' continued to be frequently mentioned in the same breath. A perusal of the results from a search on the Google News feed indicated a variety of permutations and contexts. For instance, reviewing European cinema's depiction of 'one of the biggest challenges facing humanity today', Steven Rose in The Guardian noted that 'a nod to the migrant crisis is almost becoming obligatory at the awards-friendly end of the business' but he reproached the often 'overly simplistic' and 'dehumanizing' treatment of the subject matter. The suggestion was that real-life events had in turn spelt a crisis of cinematic form: 'the personal stories of immigrants and refugees are often highly dramatic and therefore ought to make great cinema, but new modes of cinema may be required' (Rose 2017). Meanwhile, on 21 December erstwhile liberal Stephen Glover declared in The Daily Mail that 'It's not racist to say that migration has fuelled the housing crisis'. Drawing on 'copper-bottomed' figures from the anti-immigration think tank Migration Watch, Glover claimed it was high net and uncontrolled immigration to the United Kingdom over the last ten years and not austerity or a lack of public investment that had increased the 'scarcity of affordable housing' - but 'political correctness' prevented politicians from 'tell[ing] the truth' (Glover 2017).

From these three examples alone it is evident that the connection between migration and crisis assumes multiple forms and is deployed for different goals: it can define and draw attention to a political issue; it can signal a new but incomplete film genre; while, in the last case, migration can be indicted as the root cause of a longstanding crisis, also in order to disavow the relevance of systemic inequalities such as institutional racism in the way housing priorities are set (Gulliver 2017). Human mobility has long been associated with the idea of crisis (Robinson 1992; Lindley 2014). Over the last ten years this connection has become 
particularly pronounced, both in light of the long-term repercussions of the economic and financial crisis of 2008 and latterly due to the marked rise in numbers of people seeking asylum in Europe.

The focus of this special issue, however, is different. It does not set out to examine a particular 'migration crisis', such as the one commonly designated by journalists, politicians, academics and the public at large to describe the high levels of maritime migration to Europe since 2015. Nor is it merely concerned to address the ways in which various economic, political and institutional crises have affected the lives of migrants or, conversely, the impact that migration has had upon such conjunctures. One of our central aims was to take stock of a decade in which crisis has not simply become the descriptor of a succession of events, but rather a paradigmatic frame for thinking about our times. In other words, crisis does not simply describe a set of conjunctures, but is specifically understood here to concomitantly operate as a powerful narrative device that, when invoked, produces a set of meanings that structure knowledge of social phenomena and, crucially, shape policy decisions, governance structures but also our own approach as academics to studying the world. The central question we posed ourselves was: how does crisis open up but also foreclose the ways in which we frame, analyse and understand contemporary migration?

In part, our goal both to confront the avowed crises involving migrants and to encourage a meta-reflection on the links between migration and crisis converged with Janet Roitman's approach in her book Anti-Crisis (2014). Rather than arguing for a 'working definition' or 'more correct meaning' of crisis, Roitman 'seek[s] to understand the kinds of work the term 'crisis' is or is not doing in the construction of narrative forms' (2014: 3). Drawing on Reinhart Koselleck's pioneering exploration of how crisis has constantly framed modern ideas of history (2006), Roitman is interested in thinking about how crisis is constituted as an object of knowledge and how its perceived ubiquity qualifies the very nature of events ranging from humanitarian crises to debt crises. Crisis itself has long been the signifier of a critical decisive moment, but of late it has come to be construed as a protracted experiential condition (Roitman 2014: 2). Crisis is posited as an epistemological impasse and is claimed to found the possibility for alternative futures (3-4). A meta-reflection on crisis thus serves to better comprehend the material effects of crisis and the practices associated with it. How, for example, has a crisis of resources - 'there simply isn't enough money' as Stephen Glover (2017) would have it - acted as an ideological justification for managing migration in a climate of austerity and welfare restructuring? Face-value acceptance of crisis narratives, moreover, can exacerbate the tendency to view and manage 
migration according to binary divisions, such as integration versus segregation, modernity versus cultural backwardness, the deserving versus the undeserving or, most notably, through the common contrived dichotomy between refugees and economic migrants (Crawley and Skleparis 2018).

Inspired by Roitman's critical reflections on the category of crisis as a 'diagnostic of the present' (2014: 4), a key goal of this special issue was to understand how social scientists can contribute to making sense of the link between migration and crisis in the particular context of Europe over the last ten years.

The result is a multiplicity of contributions that examine migration as both an object and subject of crisis. Crisis, whether as an 'objective' state of affairs (economic, political, environmental, humanitarian, etc.) or as a performative discourse, shapes migrants' experiences in many ways. It may be implicated in people's decision to move to a different country, to take the risk of crossing the sea, or to adopt other strategies of survival. However, migration is not a collateral effect of crisis but plays a crucial role in how crisis reveals itself (Lindley, 2014). As a number of articles in this special issue demonstrate, migrants appropriate the event and the language of crisis to transform and adapt social relations and their environment, at both the individual and collective level.

This is not the first time this journal has spotlighted the question of crisis. Indeed, the 2014 special issue had at its theme 'Sociology and the Global Economics Crisis'. The editors' ambitious aim was to demonstrate how sociology as a discipline could still have a word on the financial and economic turmoil of the previous years and make sense of its consequences on the lives of individuals, and in doing so 'begin to produce knowledge that better appreciates its own limits and barriers' (Dinerstein et al., 2014: 861).

This special issue revisits the issue of crisis but with some notable differences. Not only are we interested to explore crisis in specific relation to migration: we also set out from the premise that crisis continues to operate as a pivotal category in public discourse and everyday life, while our principal point of reference is Europe rather than the United Kingdom and the wider Anglophone world. It builds on a small conference with the same title organized at Middlesex University in April 2015, which brought together the different, overlapping interests of the three editors. This conference preceded the beginning of the socalled 'refugee crisis' by a few months but 'crisis' had already been woven into public and political narratives about migration across Europe and intersected other crises, such as the institutional crisis of the European Union and the Greek debt crisis. Moreover, the conference took place just over a year before the referendum on the United Kingdom's 
continued membership of the European Union, although during the course of 2015 part of the British press was already setting the tone of the impending leave campaign by frequently emblazoning front pages with news about a 'migration crisis' encroaching on the nation.

Our choice to look at Europe as a broad geo-political and socio-cultural setting is not based on the assumption that the migration-crisis link is somehow an exclusive concern of this continent. Besides the fact that crisis and its multiple equivalents in other languages may (or may not be) coupled with understandings of human mobility in other parts of the globe, we fully acknowledge that, contrary to common perceptions (including those of Sebastian Kurz), the greater part of international migration takes place within the Global South. Indeed, public pronouncements about the 'worst refugee crisis since the Second World War' tend to overlook the fact that the vast majority of internationally displaced Syrians continue to reside in the Middle East, while the bulk of sub-Saharan migrants move within Africa.

Our focus on Europe was rather determined by other reasons. First, it has endured and has been reshaped by multiple, overlapping crises. Key defining moments during this period - from the rollout of austerity politics to popular protests in cities across Europe have been read through the prism of an unfolding financial crisis, while the European Union has found itself increasingly embroiled in institutional crises that test its very survival. The effects of these crises have been deep and migration has often been seen to be part of them. In this respect, Brexit can be considered paradigmatic of how the intersection of migration and crisis may impact upon public opinion and institutional choices, the effects of which resonate far beyond the boundaries of nation states.

Second, by the time we came to write the proposal for this special issue in April 2016, the dramatic increase in maritime migration across the central and eastern Mediterranean Sea had already started to rapidly unfold and had starkly revealed Europe's political and organizational fragility in responding to these unprecedented flows.

Finally, and most important of all, we live and work in European countries and have observed the unfolding of migration and crisis in all its aspects on a daily basis. We chose Europe because we can see the effects of these multiple crises in our research on migrants and migration, in the migrants who lose their jobs, who die at sea or are deported but also in those who challenge crisis in their attempt to cross the borders, engage in struggles or reinvent their lives. We have also witnessed how migration has been politicized and used to increase the fortunes of nationalist and populist right parties and movements. We therefore 
set out to better understand public discourses, policy decisions, rhetorical narratives, human consequences and social change across multiple sites have come to be implicated in and generated by the convergence between migration and crisis.

Our quest to explore these issues is inevitably incomplete as we continue to live through declared 'crises' that shape and are shaped by human mobility. It is also incomplete because, like any special issue, the following collection of papers does not purport to be an exhaustive reflection of the questions in hand. There are noticeable absences: for instance, there are no articles specifically dedicated to the United Kingdom. We believe, however, that the contributions together can offer a more robust and critical engagement with crisis and migration, and can hopefully inspire further research.

\section{The contributions}

The papers we selected for this special issue can be grouped according to four broad thematic strands that address and reflect upon different aspects of the migration-crisis nexus. The first strand considers the multifarious relationships between the economic crisis and migrant workers and their families. Johanna Neuhauser draws on the classic Marxist notion of the reserve army of labour to critically address how Latin American migrant workers in Spain are affected by and respond to 'post-crisis' discourses. Offering a gendered perspective on the cyclical and selective inclusion of migrants in the Spanish labour market, Neuhauser argues that crisis-hit sectors look different when it comes to the predominantly feminised sector of domestic labour. Low-skilled migrant women working in domestic services are not equally affected by the cyclical effects of economic crises because affective and reproductive labour is constantly needed and is not subjected to the same inelastic demand that characterises masculinised sectors such as construction. According to feminist political economy, precarious work conditions and job insecurity are the norm in feminised sectors because reproductive labour and domestic work are under-valued in capitalism. The impact of economic crises upon the employment conditions and citizenship rights are also evident in Francesco Della Puppa's paper on migrants' labour mobility strategies to meet the requirements for family reunification. Looking specifically at Moroccan and Bangladeshi members of reunited migrant families in north-east Italy, Della Puppa shows the complex and often painful process of further separation that reunified families endure in order to deal with the consequences of the economic crisis. Family unity does not represent a definitive and lasting achievement but is a condition that must be constantly protected in order to fulfil the requirements imposed by reunification policies. Migrant families must undertake various 
forms of mobility and redefine their daily geographies to maintain their housing, occupational and economic standards and sometimes may move to other countries to preserve their unity. In response to the crisis, migrants appropriate the instruments of citizenship in order to increase their mobility capital and the opportunity to stay in Europe. Switching to labour migration within the European Union, Jean-Michael Lafleur and Elsa Mescoli approach the issue of free movement and the tightening of welfare entitlements through the example of Italian workers in Belgium. In this piece, the economic crisis serves simultaneously as a rhetorical device and as a policy dispositif to regulate both migration and access to welfare. The authors question the traditional assumption of intra-EU mobility as unproblematic from the receiving societies' viewpoint, arguing that the crisis has changed this perception. EU citizens who use certain types of welfare provisions can find themselves undocumented and even served with a deportation order, all of which functions to increase their vulnerability and lack of social protection. In this context, welfare policies have become instrumental for limiting the mobility of certain EU migrants on the basis of the increasingly relevant demarcation between deserving and undeserving migrants.

The second thematic strand coalesces around the Mediterranean in crisis, where authors address aspects of border management and governance. Nando Sigona and Simon MacMahon draw upon a large sample of interviews with migrants and key stakeholders in Italy to examine the experiences of people arriving by boat from Africa and the Middle East. The authors argue that crisis talk in the region has been used to renew the efforts by the European Union and its member states to control and reduce migration to and across the Central Mediterranean. However, the significant transformations in the governance of mobility and borders before, during and after sea crossings have not significantly reduced the flows. On the contrary, flows have since persisted as people have continued to attempt the journey and many die in the Mediterranean. The mismatch between migration dynamics and the assumptions that underpin policy measures are most evident before the journey when assumptions are made about the 'economic' nature of African mobility, at sea when migrants are rescued, and at disembarkation when migrants' deservingness of international protection is approximately assessed. It is precisely at this 'disjunction' that a crisis narrative depicting migration as uncontrolled and directed straight towards Europe is constructed, leading to a transformation of the governance of mobility. The relationship between the inconsistent quantification of migrant deaths in the Mediterranean and European border policy is at the centre of the article by Rob Gruijters and Elias Steinhilper. The authors aim to fill a gap in the area of border studies by longitudinally assessing recent data sources on migration and 
mortality through an analysis of absolute and relative mortality risks between 2009 and 2016 . According to the authors, 'border deaths' have been politicised by two opposing agendas. On the one hand, a dominant narrative frames border deaths as the result of Europe's inability to control its external borders and asks for more measures to prevent irregular migration. On the other hand, the humanitarian narrative sees deterrence as the cause of the increasing death toll, rather than its solution. The authors also question the dominant deterrence-oriented policy narrative and point out the continuing failure of European authorities to provide a comprehensive answer to the crisis.

The third strand we have identified is the increasing politicisation of the 'migration crisis' since the annus criticus of 2015. Two national cases at the forefront of the migration crisis in 2015 are examined with a particular focus on media and political discourse. Using the case of Germany, Billy Holzberg, Kristina Kolbe and Rafal Zaborowski investigate the politicisation of the migration crisis and how the shifting figure of the un/deserving refugee is represented in key media outlets. The authors suggest that this figure is constructed and measured against the ideal of the German nation in three spheres of national life - economic productivity, state security, and gender relations. Migrants and asylum seekers during the period were framed according to dichotomous definitions such as costly/beneficial, destabilizing/assimilable and misogynist/victimized. Holzberg, Kolbe and Rafal Zaborowski’s analysis shows that even amidst the often-celebrated 'welcoming culture' that emerged in Germany in 2015, humanitarian responses in the media were always contingent upon the rejection of those considered to be undeserving and threatening. In a similar vein, Ákos Bocskor provides a discourse analysis of political discourses underlying the government's national consultation on migration on the eve of the 'summer of migration' in Hungary. By adopting a discoursehistorical approach, the paper examines how the contents and language of the consultation drew upon the discursive and political repertoires of the post-2010 governments of Viktor Orbán but were also underpinned by a longer history of Hungary’s relationship with migration and diversity. Bocksor highlights that the document used to prepare the national consultation $-\mathrm{a}$ foreword addressing Hungarian citizens and written in the name of Viktor Orbán - and the questionnaire were highly manipulative and built on the narratives of danger and securitization. Given the overwhelming consensus with the governmental standpoint, the government used the results to justify and legitimise restrictive political measures including the subsequent construction of the border barrier along the country's southern border with Serbia. 
The final thematic strand addresses everyday experiences of and responses to the 'refugee crisis' on the part of migrants, activists and local people. Both articles draw on extensive ethnographic fieldwork in Germany, but in markedly different geographic contexts and from different perspectives. While the first article focuses on a rural area of central Germany and offers a reflection on how local people reacted to the arrival of Middle Eastern asylum seekers, the second article focuses on the self-organised mobilisation of asylum seekers and their supporters in Berlin. Jan-Jonathan Bock's article narrates the impact of an emergency reception centre upon the inhabitants of a small town in the Harz mountains that had already been experiencing long-term socio-economic decline. In this particular setting, Bock examines how some people not only overcame their initial misgivings to work and volunteer in the reception centre but also started to question the very meaning of 'crisis', while others continued to frame local developments according the dominant media representations of the Flüchtlingskrise. The article challenges mainstream understandings of 'refugee crisis' by highlighting how socio-economic and historical factors differently influence the ways in which ideas about ethnic diversity, insufficient state management, weak economic prospects and hope intersect and shape attitudes towards migration. The repositioning of national and international borders in a relatively remote settlement in central Germany led to collective feelings of anxiety on the part of the local population but also to the acquisition of new forms of knowledge that opened up possibilities for shifting discourses and practices. Elena Fontanari and Maurizio Ambrosini's article is based on ethnographic research with refugees between Italy and Germany and investigates the tensions between national and international migration policy and the collective actions of the refugees and their supporters. The article focuses on a protest event staged in Berlin between 2012 and 2014 by the so-called 'Lampedusa refugees': migrants who had fled Libya during the 2011 war and who had reached other European destinations after obtaining humanitarian protection in Italy. Looking beyond the concepts of 'refugee crisis', 'humanitarian crisis' and 'economic crisis', the authors show how the migrants' precarious legal status worked to affect the structures and processes of social control that govern migrant mobility towards and within Europe.

Although the support of local activists was crucial in preventing the 'Lampedusa people' from being politically and socially marginalised, the study explores how migrants were able to build interstitial spaces of autonomy through their own everyday practices.

Following the main section of nine articles are three short review essays that consider the ways in which crisis has been publicly associated with migration in Germany, Poland and Greece. The goal here is to demonstrate how the history of lexical use and the semantics of 
'crisis' differ markedly across national and linguistic contexts. The special issue ends with two extended book reviews. The first explores Russian academic debates around migration, highlighting theoretical, empirical and policy issues that are specific to the former Soviet Union. The second critically reviews Alexander Betts and Paul Collier's influential book Refuge. Transforming a Broken Refugee System.

In sum, while it has never been our intention to see crisis as existing merely in discourse, but to recognise that it also differently refers to a real set of circumstances, we broadly agree that it has become 'utterly banal' (New Keywords Collective 2016) to talk of a 'migration crisis in Europe' in and of itself without attending to the ways in which this is constructed in relation to other places, other times and other people. By seeing migration and crisis in relation to each other rather than assuming the 'migration crisis' as an already given event opens up the possibility to move beyond the unreflexive use of crisis as a normative device and paradigmatic frame that continues to shape our times.

\section{References}

Crawley, H and Skleparis, D (2018) Refugees, migrants, neither, both: categorical fetishism and the politics of bounding in Europe's 'migration crisis' Journal of Ethnic and Migration Studies 44 (1): 48-64

Dinerstein AC, Schwartz G and Taylor G (2014) Sociological Imagination as Social Critique: Interrogating the 'Global Economic Crisis'. Sociology 48 (5): 859-868.

Glover, Stephen (2017) It's not racist to say that migration has fuelled the housing crisis. So why won’t any politician dare do it? Daily Mail, 21 December. Available at: http://www.dailymail.co.uk/debate/article-5200603/Stephen-Glover-migration-housingcrisis.html

Koselleck R (2006) Crisis. Journal of the History of Ideas 67 (2): 357-400.

Kurz, S (2017) Only by regaining control can we solve the migration and refugee crisis. Time, 18 December. Available at: http://time.com/5068561/sebastian-kurz-austria-chancellormigrant-crisis/ 
Gulliver, K (2017) Britain's housing crisis is racist - we need to talk about it Guardian, 6 July. Available at: https://www.theguardian.com/housing-network/2017/jul/06/britain-housingcrisis-racist-bme-homelessness

Lindley A (2014) Exploring crisis and migration: concepts and issues. In: Lindley A (ed.) Crisis and migration: Critical Perspectives. London: Routledge, pp. 1-23.

New Keywords Collective (2016) Europe/Crisis: New Keywords of 'the Crisis' in and of 'Europe'. Near Futures Online 1 (1): 1-45.

Robinson V (1992) Geographers and Refugee Studies: A report on the international conference 'The Refugee Crisis: Geographical Perspectives on Forced Migration' held at Kings College, London, 18-20 September 1991. Journal of Refugee Studies 5 (1): 68-72.

Roitman J (2014) Anti-crisis. Durham: Duke University Press.

Rose, Steve (2017) 'They're usually either enemies or victims': the refugee crisis on screen, The Guardian, 1 December. Available at: https://www.theguardian.com/film/2017/dec/01/theyre-usually-either-enemies-or-victims-therefugee-crisis-on-screen

Nick Dines is a Research Fellow at the Robert Schuman Centre for Advanced Studies at the European University Institute, Florence, Italy. His research interests include migration and cities, migrant labour, urban ethnography and critical heritage studies. He has published numerous journal articles and book chapters on these topics and he is also the author of the monograph Tuff City: Contested Space and Urban Change in Central Naples (Berghahn, 2012). He is currently developing new research that investigates the management of cultural diversity in the cities of Rabat and Cape Town.

Nicola Montagna is Senior Lecturer in Sociology at the Middlesex University with research interests in international migration, migration policies, migrant activism and social movements. Recent publications include 'Thinking Lampedusa: border construction, the spectacle of bare life and the productivity of migrants' (with N. Dines and V. Ruggiero; 
Ethnic and Racial Studies, 2015) 'The contestation of space in Milan's Chinatown' (City: analysis of urban trends, culture, theory, policy, action, 2016) and 'Dominant or subordinate? The relational dynamics in a protest cycle for undocumented migrant rights' (Ethnic and Racial Studies, 2018).

Elena Vacchelli is a Senior Lecturer in the Department of History, Politics and Social Sciences at the University of Greenwich. Elena's areas of expertise include migration, diversity and social inequality; gender and space; embodied, art-based and digital research approaches. The outputs from Elena's research have been published in several leading peerreviewed international journals and her track record includes research reports resulting from research activities with European institutions, third sector organisations and local authorities. For further details please see Elena's university profile: https://www.gre.ac.uk/ach/study/hpss/staff/elena-vacchelli 